\title{
Stigma Related to Tuberculosis Among Patients Attending DOTS Clinics of Dharan Municipality Aryal $S,{ }^{1}$ Badhu $A,{ }^{1}$ Pandey $S,{ }^{2}$ Bhandari $A,{ }^{2}$ Khatiwoda $P^{3}$. Khatiwada $P,{ }^{4}$ Giri $A^{4}$
}

\author{
${ }^{1}$ College of Nursing \\ ${ }^{2}$ College of Medicine \\ B.P. Koirala Institute of Health Sciences \\ Ghopa, Dharan, Nepal \\ ${ }^{3}$ Manipal College of Medical Sciences \\ Pokhara, Nepal \\ ${ }^{4}$ Richa Bajimaya Memorial Foundation
}

Corresponding Author

Shrijana Aryal

College of Nursing

B P Koirala Institiute of Health Sciences

Ghopa, Dharan, Nepal. (Now: Miami Univerity, Ohio, USA).

Email: shrijanaryal@gmail.com

\section{Citation}

Aryal S, Badhu A, Pandey S, Bhandari A, Khatiwoda P, Khatiwada $P$, et al. Stigma related to Tuberculosis among patients attending DOTS clinics of Dharan Municipality. Kathmandu Univ Med J 2012;37(1)48-52.

\begin{abstract}
Background

The patients suffering from tuberculosis are receiving shame and unfair treatment from the people living around them within their own society attending DOTS clinic of Dharan municipality.
\end{abstract}

\section{Objective}

To assess the stigma experienced by tuberculosis patients and to find out the association between stigma experienced by Tuberculosis patient and the selected variables (socio-demographic characteristics, clinical profile and illness experience).

\section{Methods}

Descriptive Cross Sectional study was done among sixty tuberculosis patients. Stratified random sampling was used to select the main center and sub center of Tuberculosis treatment and population proportionate simple random sampling using lottery method was done. Data was collected using predesigned, pretested performa from Explanatory Model Interview Catalogue developed by World Health Organization.

\section{Results}

The study revealed that $63.3 \%$ of the subjects were stigmatized. There was association between stigma and variables such as occupation, monthly family income and past history of Tuberculosis. There was also association of stigma with treatment phase, category of the patient and past outcome of illness.

\section{Conclusion}

Due to lack of knowledge and awareness about Tuberculosis, many patients were stigmatized. Efforts should be made to educate the public about Tuberculosis to reduce stigma experienced by Tuberculosis patients and improve the compliance of the patient.

\section{KEY WORDS}

direct observed treatment therapy, stigma, tuberculosis

\section{INTRODUCTION}

Tuberculosis (TB) is a major cause of illness and death worldwide, especially in Asia and Africa. ${ }^{1}$ Globally, 9.2 million new cases and 1.7 million deaths from TB occurred in 2006, of which 0.7 million cases and 0.2 million deaths were in HIV-positive people. ${ }^{1}$ It is estimated that nearly half of the 1.7 billion people in the region have been infected with tuberculosis. The South-East Asia Region, with 4.97 million TB cases, carries over one-third of the global burden of TB. ${ }^{2}$ In Nepal, about $45 \%$ of the total population is infected with TB, out of which $60 \%$ are adult. Every year, 40,000 people develop active TB, of whom 20,000 are able to spread the disease to others. ${ }^{3}$
The social stigma is recognized as an important barrier for successful care of people affected by tuberculosis. Tuberculosis has been and is still considered as a 'dirty disease', 'a death penalty' or as affecting 'guilty people'. . $^{4-6}$ In some setting TB is considered to be an inherited and/or incurable disease associated with unclean or undesirable habits or livelihoods. These perceptions are often reinforced in lower socio economic status group by impaired access to information and when the costs of reaching diagnosis and cure are out of reach. Widespread perception to this associated stigma, leads to fear of loss of employment and income, social exclusion and diminished 
marriage prospects. ${ }^{7-9}$ Women more often than man, face very different and sometimes extreme reactions to TB and stigma, this fear can promote denial, undermining self-esteem and ultimately, prevent timely diagnosis and effective treatment of TB. ${ }^{10,11}$

This study examines the locally relevant features of TB related stigma among the patients seeking treatment in BP Koirala Institute of Health Sciences (BPKIHS), Direct Observed Treatment Therapy (DOTS) Centre, main center of TB treatment and its subcenter of Dharan Municipality.

\section{METHODS}

A descriptive cross sectional study was conducted in BPKIHS DOTS clinics of Dharan Municipality from September 2008 to May 2010. All the TB patients who were registered from BPKIHS main center and are under anti tuberculosis treatment in the main center and sub centers of Dharan Municipality were included in the study. The semi structured interview schedule was adopted from Explanatory model interview catalogue (EMIC) developed by WHO/TDR as a research instrument. ${ }^{6}$ The pretest was done among 10 patients under anti tuberculosis treatment. Thirteen percent of the patients were found to be stigmatized among the total. Total TB patients registered in fiscal year 2007/2008 from BPKIHS main center of Dharan Municipality was $397 .{ }^{12}$ At $13 \%$ prevalence rate of stigma and $95 \%$ confidence interval and $80 \%$ power, the sample size was taken as sixty. Stratified random sampling was used to select the main center and sub-center of TB treatment from Dharan Municipality taking each center/ sub-center as strata. The selected centers/sub-centers were BPKIHS, Dharan-8, Dharan- 14 and Dharan -16. Population proportionate simple random sampling using lottery method was done among the patients to select the sample. Consent was taken from the patients at the time of interview and with the hospital ethical committee. All the recorded TB patients of Dharan Municipality who met the inclusion criteria were taken as a sample.

The interview schedule consists of socio demographic profile, review of record, illness experience related questions, and stigma related questionnaire. The stigma related questionnaire consisted of 17 items. Responses were coded on a $0-3$ ordinal scale $(0=$ no, $1=$ uncertain, 2 = possibly and $3=$ yes). Items were scored on 4 point likert scale (3-0 with 3 = yes, 2 = possibly, 1 = uncertain and $0=$ no). Two out of 17 item-number 2 and 12 were reverse scored as these are negatively formulated so that the higher the score the more positive the reading, as with the positively formulated items. Maximum obtainable score was 51 and minimum score was 0 .

The standardized tool was slightly modified to use in local context. The modified tool was pretested for its validity. Data was entered in MS- Excel 2007 and converted into SPSS PC+15.0 version for statistical analysis. Descriptive able 1. Distribution of Stigma Score

\begin{tabular}{|lll|}
\hline Stigma & No. of respondents (\%) & $\begin{array}{l}\text { Median score (inter- } \\
\text { quartile range) }\end{array}$ \\
\hline Experienced & $38(63.3)$ & $65.69(56.86-72.55)$ \\
\hline Not experienced & $22(36.7)$ & $27.45(15.20-36.27)$ \\
\hline Total & $60(100)$ & $55.88(32.35-66.67)$ \\
\hline
\end{tabular}

Table 2. Association between Stigma and Demographic Variables.

\begin{tabular}{|c|c|c|c|}
\hline \multirow{2}{*}{$\begin{array}{l}\text { Socio demographic } \\
\text { characteristics }\end{array}$} & \multicolumn{2}{|l|}{ Stigma } & \multirow{2}{*}{$\begin{array}{l}p \text { value } \\
\text { (chi }^{2} \\
\text { test) }\end{array}$} \\
\hline & $\begin{array}{l}\text { Not experienced } \\
n(\%)\end{array}$ & $\begin{array}{l}\text { Experienced } \\
\mathrm{n}(\%)\end{array}$ & \\
\hline \multicolumn{4}{|l|}{ Age group } \\
\hline$<30$ & $12(40)$ & $18(60)$ & 0.592 \\
\hline$\geq 30$ & $10(33.33)$ & $20(66.67)$ & \\
\hline \multicolumn{4}{|l|}{ Occupation } \\
\hline Independent & $22(43.13)$ & $19(56.87)$ & $<0.001^{*}$ \\
\hline Dependent & $0(0)$ & 19(100) & \\
\hline \multicolumn{4}{|l|}{ Sex } \\
\hline Female & $6(28.57)$ & $15(71.43)$ & 0.340 \\
\hline Male & $16(41.03)$ & $23(58.97)$ & \\
\hline \multicolumn{4}{|l|}{ Religion } \\
\hline Hindu & $18(39.13)$ & $28(60.87)$ & 0.350 \\
\hline Others & $4(28.57)$ & $10(71.43)$ & \\
\hline \multicolumn{4}{|l|}{ Ethnicity } \\
\hline Caste 2 & $12(32.43)$ & $25(67.57)$ & 0.38 \\
\hline Others & $10(43.47)$ & $13(56.53)$ & \\
\hline \multicolumn{4}{|l|}{ Marital status } \\
\hline Married & $12(33.33)$ & $24(66.67)$ & 0.512 \\
\hline Unmarried & $10(41.67)$ & $14(58.33)$ & \\
\hline \multicolumn{4}{|l|}{ Education } \\
\hline Illiterate & $4(26.67)$ & $11(73.33)$ & $0.272^{\wedge}$ \\
\hline Literate & $18(40)$ & $27(60)$ & \\
\hline \multicolumn{4}{|l|}{ Total family members } \\
\hline$<6$ & $11(39.28)$ & $17(60.72)$ & 0.694 \\
\hline$\geq 6$ & $11(34.37)$ & $21(65.63)$ & \\
\hline \multicolumn{4}{|c|}{ Monthly family income } \\
\hline$<5000$ & $1(9.09)$ & $10(90.91)$ & $0.032 *$ \\
\hline 5000-10000 & $13(37.14)$ & $22(62.86)$ & \\
\hline$\geq 10000$ & $8(57.14)$ & $6(42.86)$ & \\
\hline \multicolumn{4}{|c|}{ Previous history of TB } \\
\hline No & 19(48.71) & $20(51.29)$ & $0.008 * \wedge$ \\
\hline Yes & $3(14.28)$ & $18(85.72)$ & \\
\hline \multicolumn{4}{|l|}{ Family history of TB } \\
\hline No & $11(36.67)$ & $19(63.33)$ & 1.000 \\
\hline Yes & $11(36.67)$ & $19(63.33)$ & \\
\hline
\end{tabular}

data was presented in tabular and graphical form while summary statistics was used to find out the association between the variables (Pearson's chi square test, Fischer exact test and Likelihood ratio chi square test). 
Table 3. Distribution of stigma score of TB patients according to the different category.

\begin{tabular}{|c|c|c|c|c|}
\hline Items & No (\%) & Uncertain (\%) & Possibly (\%) & Yes (\%) \\
\hline Desire to keep others from knowing & 35 & 1.7 & 3.3 & 60 \\
\hline Did not disclose to confident $*$ & 86.7 & 0 & 3.3 & 10 \\
\hline Think less of yourself & 35 & 3.3 & 5 & 56.7 \\
\hline Shamed Or Embarrassed & 28.3 & 6.7 & 6.7 & 58.3 \\
\hline Others would think less of you & 28.3 & 8.3 & 8.3 & 55 \\
\hline Adverse effect on others & 25 & 11.7 & 21.7 & 41.7 \\
\hline Others have avoided you & 26.7 & 13.3 & 16.7 & 43.3 \\
\hline Others refuse to visit & 45 & 18.3 & 10 & 26.7 \\
\hline Others would think less of patient's family & 23.3 & 23.3 & 18.3 & 35 \\
\hline Problems for your children & 26.7 & 8.3 & 11.7 & 53.3 \\
\hline Problem getting married despite cure & 26.7 & 28.3 & 20 & 25 \\
\hline Did not expect support from spouse * & 70 & 1.7 & 28.3 & 0 \\
\hline Other problem in marriage(after cure) & 26.7 & 13.3 & 11.7 & 48.3 \\
\hline Problem for the relative to marry & 45 & 26.7 & 10 & 18.3 \\
\hline Asked to stay away from work & 51.7 & 5 & 6.7 & 36.7 \\
\hline Decided to stay away from work, groups & 30 & 0 & 5 & 65 \\
\hline Presumed other health problems & 33.3 & 13.3 & 13.3 & 40 \\
\hline
\end{tabular}

*The item two and twelve are reverse scored $\mathbf{n}=\mathbf{6 0}$

\section{RESULTS}

\section{Demographic Patterns}

Out of sixty eligible candidates, 39 were males while 21 were females. Among these 30 of them were of the age less than 30 while 30 of them were of age 30 or more than 30 . Thirty seven of the respondents were of the caste 2 disadvantaged janajati categories. Twenty four were married and 45 of were literate. Majority of the respondents (35) had monthly family income between Nrs. 5000-10000. Only 21 of them had previous history of TB and 30 of them had family history of TB. Total obtainable score to was 51, and a score of more than or equal to 25.5 were considered as stigmatized. Table 1 shows that out of total score of 51 , the median score was 55.88. Thirty eight respondents who had experienced stigma had median score of 65.69. Eighty percent have first discussed their problem with their family members, $6.7 \%$ have first discussed their problem with their close friends while around $13.3 \%$ haven't discussed their problem with anyone.

Table 2 shows that $66.67 \%$ of the responses, aged $\geq 30$ years had experienced some kind of stigma. Respondents who were independent workers (56.87\%) experienced stigma with significant association (0.000). Female patients $(71.43 \%)$ showed more stigma than male patients (58.97\%), however no significantly associated could be shown. Married (66.67\%), illiterate (73.33\%), and family with more than or equal to 6 family members (65.63\%) experienced higher level of stigma than their counterparts. Respondents with monthly income less than NRs.5000 and those with previous history of TB (85.72\%) experienced more stigma and these were statistically significant.
Table 4. Association of stigma with clinical profile of patient. $n=60$

\begin{tabular}{|llll|}
\hline Clinical profile & $\begin{array}{l}\text { Stigma } \\
\text { Not experienced } \\
n(\%)\end{array}$ & $\begin{array}{l}\text { Experienced } \\
n(\%)\end{array}$ & $\begin{array}{l}\text { p value } \\
\text { (chi }^{2} \text { test) }\end{array}$ \\
\hline Disease category & & $8(66.67)$ & $0.534^{\wedge}$ \\
\hline Extra-pulmonary TB & $4(33.33)$ & $30(62.5)$ & \\
\hline Pulmonary TB & $18(37.5)$ & $27(61.36)$ & 0.219 \\
\hline Treatment category & & $7(87.5)$ & \\
\hline Category 1 & $17(38.63)$ & $4(50)$ & \\
\hline Category 2 & $1(12.5)$ & & \\
\hline Category 3 & $4(50)$ & $16(45.72)$ & $0.022^{* \wedge}$ \\
\hline Treatment phase & & $22(88)$ & \\
\hline Continuous & $19(54.28)$ & & \\
\hline Intensive & $3(12)$ & $27(56.25)$ & $0.021^{* \wedge}$ \\
\hline Category of patient & & $11(91.67)$ & \\
\hline New & $21(43.75)$ & & \\
\hline Others & $1(8.33)$ & & \\
\hline
\end{tabular}

*p value significant, ^ Fischer exact test

\section{Distribution}

Table 3 shows that sixty percent of the patients desired to keep people from knowing about their disease. Fifty six percent $(56.7 \%)$ thought less about themselves because of the disease. Only $41.7 \%$ believed that their disease will cause adverse effect on others. Forty three percent (43.3\%) of the respondents thought that others have avoided them because of the disease and $37 \%$ of the patient was asked to stay away from work. A total of $25 \%$ had an opinion of anticipating difficulty during their marriage, and $48.3 \%$ of the patient felt that they will have other problem in their 
marriage even after cure. TB-related stigma and social discrimination were particularly troubling for women because they threatened their ability to marry or put them at risk of divorce.

\section{Clinical profile of patient}

Those with extra-pulmonary tuberculosis (66.67\%) experienced more stigma than those with pulmonary tuberculosis. Most of the patient under category 2 treatment category (87.5\%) were more on distress than others $(p=0.219)$. Most of the patients under intensive phase (88\%) are more troubled than those on continuous $(p=0.022)$. RAD, relapse, and treatment failure were more stigmatized than new (91.67\%) cases $(p=0.023)$.

\section{DISCUSSION}

Findings from this cross-site analysis study indicate that social and cultural factors that operate in the context play a major role in level of mental discomfort faced by patients who have Tuberculosis. The first objective of this study was to assess stigma experienced by TB patients. Results showed that $63.3 \%$ of the TB patients had experienced stigma, similar to a study conducted in southern Thailand by Rie AV, which shows that stigma is present on patients perspective towards TB. ${ }^{13}$

Most of the patients revealed that they don't want others to know about the disease. Some of the patients also revealed that they go to the DOTS center which is farther from their home so that nobody knows that they are taking TB drugs. Similar study conducted by Atre SR et al showed that most of the male and female vignettes (75\%) wanted to hide disease from others. ${ }^{4}$ A study conducted in Southern India showed that $6.7 \%$ of patients gave wrong names and addresses to avoid being exposed as TB patients to their acquaintances. ${ }^{14}$

In this study most of the patients have first discussed their problem with their family members (80\%), 6.7\% have first discussed their problem with their close friends while around $13.3 \%$ haven't discussed their problem with anyone. This finding is supported by the study conducted by Zolowere Dwhich which showed that majority of patients reported having disclosed their disease status to close family members, such as spouses, siblings and parents; only a few had disclosed their status to their children. The most common way of disclosure was through personal discussion between the patient and their significant others. ${ }^{15}$ In the other study conducted in southern India showed that many men felt inhibited from revealing the diagnosis to friends $(43 \%)$ and even to their spouse (16\%). ${ }^{14}$

Most of the patients said that they have impaired selfesteem, felt shamed or embarrassed, and have felt less respect from others in the society. One of the patient said he is even treated badly even by his own wife since he couldn't earn money because of the disease. Some of them even told that they are treated very badly at their home by their own family members which have affected much on their self-esteem. Greater number of patients thought disease might cause adverse effect on others even after treatment because the germs may live on their breath forever and got transmitted. Even though other persons didn't verbalize that they don't want to sit nearer to the TB patients but they show through their behavior that they don't want TB patients near them. This was revealed by one of the TB patients.

Few have felt that the other people don't want to come to their home. When asked about what may be the reason they told that most of them have TB patients in their home itself at one of the time. The study showed that if neighbors, colleagues or others in the community know about the disease they might avoid the family. The study conducted by Lifeooghe Rrevealed that the TB patients perceive their neighbors and friends attitudes towards them as rather negative. ${ }^{16}$ TB patients felt they are feared and that contact with them is avoided. This negative attitude persists during the first months of treatment, as neighbors and friends do not seem to be aware that TB is no longer contagious after a few weeks of treatment. ${ }^{16}$

Most of the patients expected support from their spouse and had also got support from spouse. Most of them agreed that the disease might create other problems in marriage even after cure. Some of them told that they can't sleep together as there is risk of transmission. Also there may be economic problem as the TB patient can't work even after treatment as they have become weak because of disease. The study done by Atre SR supports this. In Bangladesh, patient's narrative showed that the association of weakness and stigma resulted from limitations on the ability to work. ${ }^{4}$ Greater no of patients told that there will be no problems for the relative to get married because of their TB.

Greater number of the patients didn't felt that they were asked to stay away from work or will be asked to stay from work. But most of them have left their work after getting TB. They also expressed that they have left going nearer to their friends or places where there is social gathering with the fear that they might infect disease to others. This is similar to the study conducted in South India which showed that stigma continued to be a significant cause of concern for patients even after completion of treatment as it interfered with social acts such as visiting friends (before treatment completion, 38\%, and after treatment completion, $20 \%$ ). ${ }^{14}$

The study findings showed that there was association between stigma and occupation. More patients who were dependent upon others (100\%) were found to have more stigma $(p<0.001)$. The study showed that more patients with income below Rs.5000 experienced more humiliations and this was statistically significant $(p=0.047)$. The study also showed that there was significant association with previous history of TB $(p=0.008)$ which showed that more patients with previous history thought of being more 
condemned. The study showed that there was association between stigma and treatment category as well as category of patient. The patients who were in intensive phase were more stigmatized $(p=0.022)$. Also the patients who fall in category other than new (RAD, relapse, treatment failure) were more stigmatized than others $(p=0.023)$. Stigma is often a product of exaggerated notions of contagiousness. Community awareness and patient education may help to mitigate the isolation and rejection of TB patients and encourage TB suspects to seek initial care.

\section{Limitation}

The study was undertaken to examine site-specific sociocultural and gender-related features of TB at designated treatment sites. Although sample sizes were moderate, they were adequate for gender comparisons within sites and analysis across sites. Clinical samples were selected to represent the patient population of the well-functioning TB control programs at the study sites, but they were not intended to represent a profile of TB for the entire country or even the community where the treatment sites are located. Because the studies were based at diverse TB clinic sites, the question of how to generalize findings must be considered carefully.

\section{REFERENCES}

1. World Health Organization [Internet]. Global tuberculosis control - 2008. WHO. [Available from :http://www.who.int/entity/tb/ publications/global_report/en/index.html]

2. World Health Organization [Internet]. Tuberculosis - TB in South-East Asia - Epidemiology. [Available from: http://www.searo.who.int/en/ Section10/Section2097/Section2100_10639.htm]

3. National Tuberculosis Control Program. Annual Report. Kathmandu (2006-2007). Kathmandu, Nepal: National Tuberculosis Centre, 2006.

4. Atre SR, Kudale AM, Moranker SN, Rangan SG, Weiss MG. Cultural concepts of tuberculosis and gender among the general population without tuberculosis in rural Maharatra. Tropical medicine and International Health 2004;9(11):1228-1238.

5. Long $\mathrm{NH}$, Johansson $\mathrm{E}$, Diwan $\mathrm{VK}$, Winkvist $\mathrm{A}$. Fear and social isolation as Consequences of tuberculosis in Vietnam: a gender analysis. Health Policy 2001; 58(1):69-81.

6. Weiss MG, Somma D, Karim F, Abouihia A, Auer C, Kemp J, et al. Cultural epidemiology of TB with reference to gender in Bangladesh, India and Malawi. Int J Tuberc Lung Dis 12(7):837-47. [Available from: http://www.who.int/tdr/publications/documents/culturalepidemiology-tb.pdf]

7. World Health Organization [Internet] . Addressing poverty in TB control, Options for National TB control programs. WHO (2005):2556. [Available from:http://whqlibdoc.who.int/hq/2005/WHO_HTM_ TB_2005.352.pdf]

8. Uplekar M W, Rangan S, Weiss M g, Ogden J, Borgdorff M W, Hudelson P. Attention to gender issues in tuberculosis control. Int J Tuberc Lung Dis 2001; 5: 220-224.

9. Thorson A, Diwan VK. gender inequalities in tuberculosis: aspects of infection, notification rates, and compliance. Curr Opin Pulm Med 2001; 7: 165-169.

\section{CONCLUSION}

The findings from this study have identified features of TB associated stigmas and local profiles of illness-related experience, meaning and behavior for patients treated in TB control programs in Nepal. The study showed that $63.3 \%$ of the patients were stigmatized. Due to lack of knowledge and awareness about TB, many patients were stigmatized. Efforts should be made to educate the public about TB to reduce stigma experienced by TB patients and improve the compliance of the patient. Health care providers should ensure that patients and their families understand the benefits of treatment and the duration of infectiousness after the start of treatment. Support to patients from community members, recovered patients and others may also facilitate de-stigmatization of TB and promote awareness of its transmission, course and cure.

\section{ACKNOWLEDGEMENT}

Researcher is deeply indebted to Professor Mitchell G. Weiss of Swiss Tropical Institute, Department of Public Health, Switzerland for providing the Explanatory Model Interview Catalogue.
10. World Health Organization [Internet] . Addressing poverty in TB control, Options for National TB control programs. WHO (2005):2556. [Available from:http://whqlibdoc.who.int/hq/2005/WHO_HTM_ TB_2005.352.pdf]

11. World Health Organization [Internet]. Gender and illness related experience meaning and behavior semi structured interviews for patients WHO/TDR collaborative research study. [Available from: http://www.searo.who.int/en/Section2100_109.htm]

12. Dharan Municipality. Annual Report 2007/2008. Dharan; Government of Nepal; 2008.p.28-9.

13. Rie AV, Sengupta S, Pungrassami P, Balthip Q, Choonuan S, Kasetjaroen $\mathrm{Y}$, et al. Measuring stigma associated with tuberculosis and HIV/AIDS in southern Thailand: exploratory and confirmatory factor analyses of two new scales. Tropical Medicine and International Health 2008;13(1):21-30.

14. Rajeswari R, Muniyandi M, Balasubramanian B, Narayanan PR. Perceptions of tuberculosis patients about their physical, mental and social well-being: a field report from south India. Social Science \& Medicine 2005; 60:1845-53.

15. Zolowere D, Manda K, Panulo BJ, Muula AS. Experiences of selfdisclosure among tuberculosis patients in rural Southern Malawi. Rural Remote Health 2008;8(4):1037.

16. Liefooghe R, Michiels N, Habib S, Moran MB, Muynck DA. Perception and social consequences of tuberculosis: a focus group study of tuberculosis patients in Sialkot, Pakistan. Social Science and Medicine 1995;41(12):1085-92. 